\title{
Direct and Indirect Forensic Age Estimation Methods for Deciduous Teeth
}

Aka P. Sema ${ }^{1}$, Yagan Murat $^{2}$, Canturk Nergis ${ }^{3}$ and Dagalp Rukiye ${ }^{4}$

${ }^{1}$ Head of Forensic Odontology Commission of Turkish Forensic Scientists Society, Ankara, Turkey.

${ }^{2}$ Institution of Forensic Medicine, Directorship of Afyonkarahisar Agency Department, Afyonkarahisar, Turkey.

${ }^{3}$ Department of Criminalistics, Institute of Forensic Sciences, Ankara University, Ankara, Turkey

${ }^{4}$ Department of Statistics, Faculty of Science, Ankara University, Ankara, Turkey.

"Corresponding author: AKA P. Sema, Head of Forensic Odontology Commission of Turkish Forensic Scientists Society, Ankara, Turkey,Tel: 905325136389; E-mail: akasema@gmail.com

Rec date: Jan 29, 2015 Acc date: Feb 19, 2015 Pub date: Feb 25, 2015

Copyright: ( 2015 Aka PS et al. This is an open-access article distributed under the terms of the Creative Commons Attribution License, which permits unrestricted use, distribution, and reproduction in any medium, provided the original author and source are credited.

\begin{abstract}
Age estimation from primary teeth is an important matter for forensic odontology, which can be found by the application of direct or indirect age estimation methods that are functions of tooth measurements. The most distinctive teeth among these are the upper central incisors, because of their early development. The aim of this study is to determine the age of fetuses or infants by measuring the tooth development directly from tooth surfaces or from indirect measurements obtained from the tooth structures on the computerized tomography digital images. The data of all measurements were statistically processed by regression analysis and regression formulas were derived.

The results revealed that age could be estimated from various tooth dimensions within an accuracy of $\pm 0-2$ weeks for both methods and therefore indirect method -which was proposed as Virtual Dental Identification (VirDent-ID) by the authors PS. Aka and N. Canturk- could be a matter of choice instead of traditional direct oral autopsy methods. The best measurements for age estimation can be obtained from the longest vertical dimension, which is the tooth height, and the best age estimation formula was also generated from the tooth height. In conclusion, age formulas derived from direct or indirect measurements of fetus or infant tooth development stages may be used as an aid for dental identification, until the completion of upper central primary tooth development.
\end{abstract}

Keywords: Forensic odontology; Age estimation; Primary teeth; Tooth measurement; Virtual dental Identification (VirDent-ID); Oral autopsy

\section{Introduction}

Forensic identification is one of the most significant issues of the forensic sciences that include the estimation of features as; age, gender, biologic varieties and stature of an individual. Among these, dental age estimation has a prime importance due to the hardness of dental tissues which can resist post mortem alterations. In this study direct and indirect methods for the age estimation of the first phase of primary (deciduous) dentition was proposed, which has been given less attention when compared to the age estimation methods for the permanent (secondary) dentition.

The most significant source of dental evidence is the oral autopsy applications, which consist of examination and evidence collection from the oral cavity of a deceased individual. In case an erupted tooth is present it has to be measured in-situ then only the crown measurements as; mesio-distal (MD), labio-lingual (LL), crown height $(\mathrm{CH})$ could be recorded and calculated for age estimation.

On the contrary, if the teeth were not erupted, then deciduous teeth germs could be extracted for diagnostic identification purposes where additionally root height $(\mathrm{RH})$, tooth height $(\mathrm{TH})$ and the crown thickness (CrT) dimensions could be measured. The authors of this study found four ATA entitled age formulas in their previous research, which were derived to give the relation of age with tooth dimensions and dedicated to the honour of the great Turkish leader Mustafa Kemal Ataturk (1881-1938) [1].

The authors also defined the age in high correlation when they formulated the head circumference with the upper tooth dimensions (LL, MD, and TH) [2]. However dental evidences could also be examined and measured indirectly from the computerized tomography (CT) digital images [3].

When required, the selected tooth specimens can be sent for Scanning Electron Microscope (SEM) examinations to detect the neonatal line, by which the viability of the deceased fetus at the time of birth could be determined. Teeth show a band type of developmental deformation landmark named as Neonatal Line (NL).

This neonatal defect is caused by the effect of metabolic stresses which blocks the formation of the tooth structures that occurs due to the birth trauma, when the fetus is passing from intra uterine to extra uterine life. Therefore teeth are accepted as indicators of live birth [4].

The aim of this research was to evaluate the best method to estimate age of a fetus or infant by measuring the tooth development of a primary tooth directly from tooth surfaces or from indirect measurements obtained from the tooth structures on the computerized tomography digital images, which is proposed as Virtual Dental Identification "VirDent-ID" by the authors PS. Aka and N. Canturk [5]. 
Citation: Aka PS, Yagan M, Canturk N , Dagalp R (2015) Direct and Indirect Forensic Age Estimation Methods for Deciduous Teeth. J Forensic

\section{Method and Material}

In the present study direct measurements of 38 upper central incisor tooth of fetuses and infants cases (9 females and 10 males) within the age range of 16 to 108 weeks (including pre and postnatal term) and dental images of 28 patients (12 females and 16 males) with known age (postnatal 1-195 weeks) were used for age estimation which is found to be the most agreeable teeth for aging due to its early eruption and early developmental completion [1].

To extract deciduous teeth germs from their sockets, "Aka-Canturk Oral Autopsy Method" was used for identification reasons, under the legal permission of the Council of Forensic Medicine, Ministry of Justice (Project number and date: B.03.1.ATK.0.01.00.08/237, May 30, 2006) and University of Ankara (Number and date of decision: 103-2692, December 4, 2006) [5]. This is a simple and accurate direct autopsy method requiring minor intervention for extracting the dental evidence, as access to the oral cavity is effortless.

During the application of this method, curved incisions were made following the ridges of maxillary and mandibular alveolar crests, and then periosteum was separated from the bone.

Extraction of teeth were done with the elevators from the mesial sites of the periodontal socket, without making any contact with the tooth germ, and then the tooth germ specimens were placed in labelled containers filled with $10 \%$ formalin preserving solution. These evidences were then photographed and measured Figure 1.

Serial photographs showing the tooth development stages of fetus and infant cases in six aspects could be found in a text and atlas which is going to be published by the authors in 2015 by CRC Press, Taylor \& Francis Group [6].

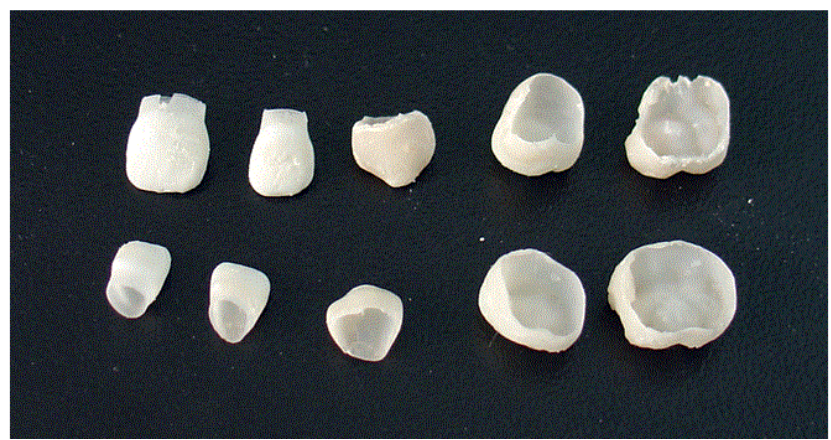

Figure 1: Dental structures of left upper and lower teeth of an infant, postnatal 34 weeks old.

To determine the age of fetuses or infants, direct measurements of the tooth were taken with two compasses (sensitive to $0.1 \mathrm{~mm}$ ); the digital Vernier compass (Mitutoyo, Japan) was used for LL, MD and TH dimensions Figure 2 and the dental metal thickness compass (Fara Dental, Germany) used for CrT dimensions.

The indirect measurements were obtained from the CT digital images with electronic callipers of $0.01 \mathrm{~mm}$ precision.

Tooth dimensions LL, MD, TH and CrT were measurements from the sagittal, coronal, and axial planes for each central incisor Figure 3.

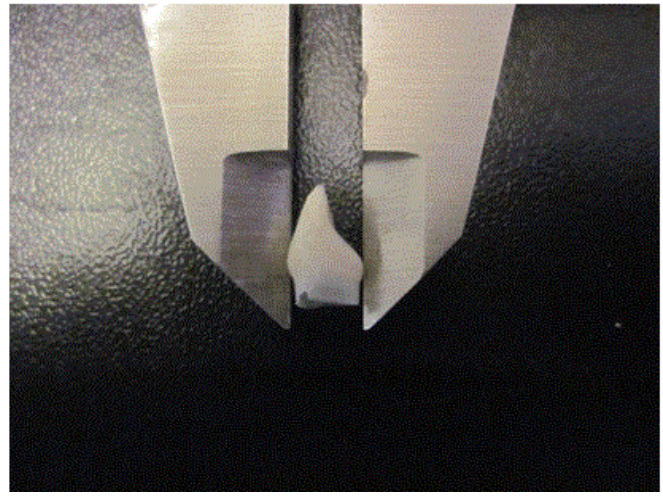

Figure 2: Direct labio-lingual tooth measurement with digital Vernier compass.

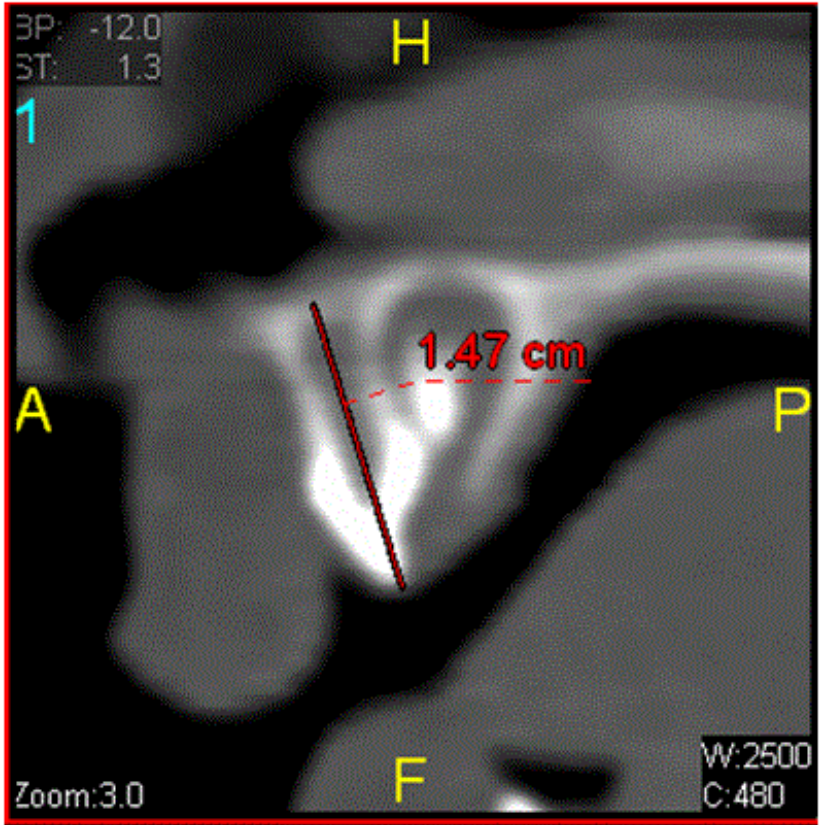

Figure 3: Indirect tooth height measurement from sagittal plane on a CT digital image.

The direct and indirectly obtained data were statistically processed by regression analysis and regression formulas were derived for the calculation of age estimation.

\section{Results}

In this research the best age estimation method for fetus or infant cases were evaluated by using direct and indirect primary tooth measurements and it is found that the longest vertical dimension which is the tooth height gave the best measurements for age estimation and the best age estimation formula was also generated from the tooth height within an accuracy of $\pm 0-2$ weeks for both direct and indirect methods as seen in Table 1. The graphics of the growth curves of $\mathrm{TH}$ are given in Figures 4 and 5. 
Citation: Aka PS, Yagan M, Canturk N , Dagalp R (2015) Direct and Indirect Forensic Age Estimation Methods for Deciduous Teeth. J Forensic

Page 3 of 3

\begin{tabular}{|l|l|l|l|l|}
\hline Variables & Formula & $\mathbf{R}^{2}$ & $\mathbf{S}^{2}$ & $\begin{array}{l}\text { Margin of } \\
\text { error for age }\end{array}$ \\
\hline Direct TH & $\begin{array}{l}\text { Ln(Age) }=3.130-0.061 \times \\
\text { Sex+0.096 } \times \mathrm{TH}+0.009 \times \\
\text { Sex } \times \mathrm{TH}\end{array}$ & 0.960 & 0.014 & \pm 1.027 \\
\hline Indirect TH & $\begin{array}{l}\text { Ln(Age) }=0.264+0.049 \times \mathrm{CT} \\
\text { Axes }+0.341 \times \mathrm{TH}-0.006 \times \\
\mathrm{CT} \text { Axes } \times \mathrm{TH}\end{array}$ & 0.946 & 0.092 & \pm 1.197 \\
\hline
\end{tabular}

Table 1: Direct and indirect age estimation formulas and their margin of errors depending on tooth height dimension

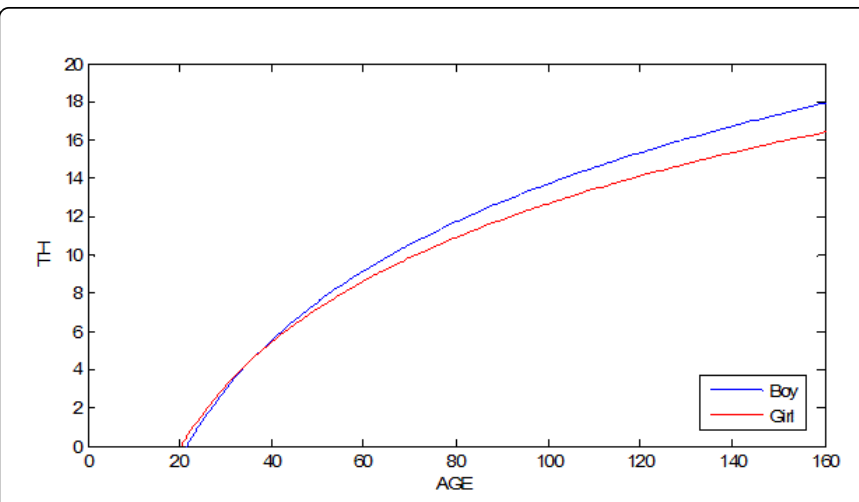

Figure 4: The graphics of TH with age for direct measurement data according to gender.

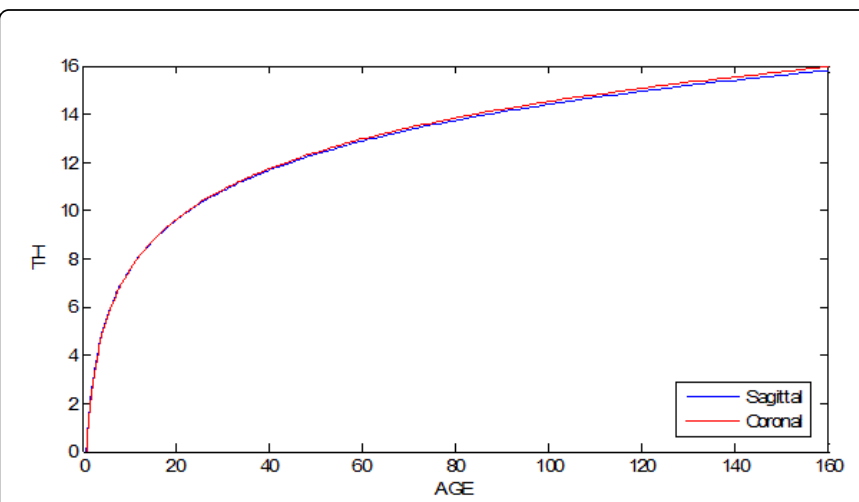

Figure 5: The graphics of TH with age for indirect measurement data obtained from sagittal and coronal directions

\section{Discussion and Conclusions}

The central incisors were found as indicative teeth and formulas derived from their tooth height measurement gave reliable age estimation during their development for both direct and indirect methods, where margin of error was $\pm 0-2$ weeks. Virtual Dental Identification (VirDent-ID) on computerized tomography digital images is a matter of choice instead of traditional oral autopsy methods using interventive surgery. The age formulas derived from direct or indirect measurements of fetus or infant primary upper central tooth, until its developmental completion may be accepted as an important source for forensic dental identification. Further reading is suggested on the subject of age estimation from primary dentition [7-10].

Presented at the "3rd International Conference on Forensic Research \& Technology”, October 06-08, 2014. San Antonio, Texas, USA.

\section{References}

1. Aka PS, Canturk N, Dagalp R, Yagan M (2009) Age determination from central incisors of fetuses and infants. Forensic Science International 184: $15-20$

2. Dagalp R, Aka PS, Canturk N, Kedici I (2014) Age estimation from fetus and infant tooth and head measurements. International Journal of Legal Medicine 128: 501-508.

3. Canturk N, Aka PS, Dagalp R, Uzun C, Canturk G (2014) Age Estimation From Deciduous Infant Tooth Through Virtual Dental Identification. Australian Journal of Forensic Sciences.

4. Canturk N, Atsu SS, Aka PS, Dagalp R (2014) Neonatal line on fetus and infant teeth: An indicator of live birth and mode of delivery. Early Human Development 90: 393-397.

5. Aka PS, Canturk N (2014) Aka Canturk Oral Autopsy Method for the Dental Identification of Fetus and Infant Cases Forensic Medicine and Anatomy Research 2: 48-50.

6. Aka PS, Yagan M, Canturk N, Dagalp R (2015) Primary Tooth Development in Infancy, A Text and Atlas, CRC Press, Taylor \& Francis Group. (Website of CRC Press, Taylor \& Francis Group)

7. Mörnstad H, Staaf V, Welander U (1994) Age estimation with the aid of tooth development: a new method based on objective measurements, Scand. J. Dent. Res. 102: 137-143.

8. Pinkham JR, Casamassimo PS, Mc Tigue MJ, Fields HW, Nowak AJ (2005) Pediatric Dentistry. Infancy Through Adolescence, 4th ed., Elsevier Inc., St. Louis.

9. Muller-Bolla M, Lupi-Pe' gorier L, Quatrehomme G, Velly AM, Bolla M (2003) Age estimation from teeth in children and adolescents, J. Forensic Sci. 48: $140-148$.

10. Cardoso HF (2007) Accuracy of developing tooth length as an estimate of age in human skeletal remains: the deciduous dentition, Forensic Sci. Int. 172: $17-22$. 